\title{
Adrenal Gland Hyperplasia III
}

National Cancer Institute

\section{Source}

National Cancer Institute. Adrenal Gland Hyperplasia III. NCI Thesaurus. Code C129302.

Decreased activity of the enzyme 21-hydroxylase, associated with mutation(s) in the CYP21A2 gene. The lack of activity of this enzyme produces a type of congenital adrenal hyperplasia (CAH) and is the cause of approximately 95\% of CAH. 